\title{
THE CONTAGION EFFECTS OF COVID-19 PANDEMIC ON CRYPTOCURRENCIES
}

\author{
Mahboob Ullah $^{1 *}$, Maria Shaikh ${ }^{2}$, Imran Abbas Jadoon ${ }^{3}$, Muhammad Azizullah Khan ${ }^{4}$, Shahida Habib Alizai ${ }^{5}$ \\ $1^{*}$ Associate Professor, Khurasan University, Nangarhar, Afghanistan; ${ }^{2}$ Associate Professor, IBA, University of Sindh \\ Jamshoro, Pakistan; ${ }^{3}$ Assistant Professor, Department of Management Sciences, Comsats University Islamabad, \\ Pakistan; ${ }^{4}$ Associate Professor, Preston University, Islamabad, Pakistan; ${ }^{5}$ Assistant Professor, Gender Development \\ Studies Department, University of Balochistan, Pakistan. \\ Email: *mahboobmails@gmail.com
}

Article History: Received on $2^{\text {nd }}$ April 2021, Revised on $15^{\text {th }}$ April 2021, Published on $19^{\text {th }}$ April 2021

\section{Abstract}

Purpose of the Study: In this research, the association between the COVID-19 pandemic and cryptocurrencies' price volatility has been examined.

Methodology: To check the contagion effects of the COVID-19 pandemic on the price volatility of cryptocurrencies: BITCOIN, LITECOIN, XRP(RIPPLE), and ETHEREUM, the prices of all four are deployed from $10^{\text {th }}$ August 2016 to 10 August 2020. The exponential generalized autoregressive conditional heteroscedastic (EGARCH) model is used to check the leverage effect exists or not. Stata 16 has been used to execute all the tests.

Main Findings: The study's findings indicated that the leverage effect on the price volatility is present for LITECOIN, XRP(RIPPLE), and ETHEREUM but not for BITCOIN.

Applications of the study: This study is significant for investors to develop strategies for investments and secure the transactions and control the creation of additional currency units. Also, it gives insight to the policy and decision-makers to articulate proper guidelines to overcome or minimize the effect of COVID-19 on cryptocurrency.

Novelty/Originality of this Study: The motive for taking the crypto market into account is that the crypto market is one of the emerging markets and has started to have significance worldwide, linking with financial markets and economic growth. The leverage effect of COVID-19 is considered in this study as the epidemic has affected the supply and demand of goods due to lockdowns, blockages, and disruptions in delivery chains that lead to undiminished economic growth.

Keywords: Bitcoin, COVID-19 Pandemic, Cryptocurrencies, Ethereum, Litecoin, Xrp(Ripple).

\section{INTRODUCTION}

The word pandemic is a Greek word and according to the modern definition, it means an epidemic that spread over a wide area (countries, continents, or the whole world). It also means geographical spread, which refers to the disease that affects the entire population of the world as a whole. According to some definitions, a true pandemic causes a high degree of mortality (death). The current example of this is the COVID-19 which starts from China as an epidemic and, in a matter of months, turns into a pandemic as it spread in the entire world. The covid-19 affects almost every part of the world. It causes a massive number of deaths and financial losses in nearly every sector of the economy.

Satoshi Nakamoto, a group knows by the pseudonym, launched Bitcoin in 2009. "As of November 2019, there were over 18 million bitcoins in circulation with a total market value of around $\$ 146$ billion." Bitcoin, the most demanded, popular, and valuable, was the first blockchain-based cryptocurrency. At this time, a wide range of cryptocurrencies with various functions and specifications are available as an alternative. Some are clones of Bitcoin, while others are currencies with different functions. There are 180 internationally recognized currencies in circulation, from the Samoan Tala to the Burmese Kyat. As with common currencies, there are a variety of cryptocurrencies. Being the first cryptocurrency, bitcoin has garnered a lot of attention from the market but at the same time competes with a dozen more promising options, including Litecoin. Litecoin, like its contemporaries, in a sense, functions as an online payment system, like PayPal or a banking network. Users can use it to transfer currencies between themselves instead of using the US dollar, Litecoin trades in units of Litecoin. This is where the similarity of Litecoin with the more traditional currency and payment system ends; it is one of the top five cryptocurrencies (Ullah, Shaikh, Channar, \& Shaikh, 2021).

Ethereum is a technology that allows you to send cryptocurrencies to anyone for a minor fee. It also runs programs that anyone can use and that no one can remove. It is a globally programmable blockchain. Ethereum is based on Bitcoin innovations, with some significant differences. Both allow you to use digital money without a payer or bank. But Ethereum is programmable so that you can use it for many diverse digital forms, even Bitcoin! It means that Ethereum is used more than just a form of payment. Ripple uses Gateway's environment, which acts as a link between the two parties in a relationship that the company desires. The Gateway acts as a debit broker that receives and sends coins to email addresses across the Ripple network (Khan, Ullah, Usman, Malik, Khan, 2020).

The existence of COVID-19 has stunned the worldwide financial and commodity markets, economic activity, employment, GDP of the countries, and the cryptocurrency market. This research shows the price volatility of 
cryptocurrencies being affected by COVID-19, focusing on the top four cryptocurrencies, BITCOIN, LITECOIN, XRP(RIPPLE), and ETHEREUM, by using the EGARCH model. "Estimation of volatility has several applications especially in trading, investment, and portfolio selection of stock and commodities market because it supports the investors in risk management, derivative pricing, hedging, and forecasting price" (Iqbal \& Mallikarjunappa, 2010). Learning about the price volatility also allows you to predict any market's direction, allowing a layman investor to have a good idea of what one can expect from the economy actions outside the stock and commodity markets (Iqbal \& Mallikarjunappa, 2011). Different methods that can be used to check the volatility include ARCH, GARCH, EGARCH, TARCH, etc.

EGARCH, which is an exponential GARCH model, is developed to capture the leverage effect. In EGARCH, "conditional distribution is heavy-tailed and skewed is proposed. The characteristics of the model, including autocorrelations, unconditional moments, and the asymptotic distribution of the maximum likelihood estimator, are portrayed" (Abdelrhim et al., 2020; Harvey \& Sucarrat, 2014). Hence, EGARCH is appropriate to estimate the leverage effect of COVID-19 on the price volatility of the four major cryptocurrencies in the world are BITCOIN, LITECOIN, XRP(RIPPLE), and ETHEREUM. The motive for taking the crypto market into account is that the crypto market is one of the emerging markets and has started to have signs worldwide, linking with financial markets and economic growth. The leverage effect of COVID-19 is considered in this study as the epidemic has affected the supply and demand of goods due to lockdowns, blockages, and disruptions in delivery Chains that lead to undiminished economic growth (Baker, 2020; Bhosale \& Mavale, 2018).

\section{RESEARCH QUESTIONS}

For the accomplishment of the aforementioned research objective, this research seeks to answer the question;

- Does the COVID-19 outbreak impact cryptocurrency price volatility?

\section{LITERATURE REVIEW}

COVID-19, a transmittable disease instigated by a newly discovered coronavirus strain that causes respiratory infections in individuals. This new species was not known until December 2019, when pneumonia of unknown cause occurred in Wuhan, China. The existence of COVID-19 has stunned the worldwide financial and commodity markets, economic activity, employment, GDP of the countries, and the cryptocurrency market. Many studies have been conducted in this regard.

Guesmi et al. (2019) analyzed the herding in cryptocurrency markets during the covid19 pandemic. Hourly prices of the four most traded cryptocurrency markets - USD, EUR, JPY, and KRW with a combination of quantitative methods were used. The results show that covid 19 does not escalate herding in cryptocurrency markets.

Mukherjee and Goswami (2017) analyzed the relationship between cryptocurrencies and deaths/cases during the covid19 pandemic. Daily prices of Bitcoin, Ethereum and Ripple, were used in US\$. The wavelet consistency analysis results showed that there was originally a negative relationship between Bitcoin and the number of confirmed cases and deaths. However, later the relationship will be positive. The results from Ethereum and Ripple are also alike but with a weaker interaction. This shows the role of cryptocurrency protection in the uncertainty caused by COVID-19. Bitcoin as a secure haven is one of the traditional storytelling of the crypto community. Since around 2013, there have been no severe financial markets to confirm or deny this story until COVID-19.

Yarovaya, Matkovskyy, and Jalan (2020) studied the volume-related relationships between Bitcoin and the two standards (S \& P500 and VIX) and compared gold as the traditional safe-haven asset. The results show that Bitcoindome's story is mainly and indirectly displayed and discussed, and gold is the winner of this competition.

Ali et al. (2020) discuss the global epidemic that has caused chaos worldwide and how it has impacted the global economy. The focus of their research is how the cryptocurrency market has been affected by this global crisis. By taking and analyzing data of 100 cryptocurrencies, their findings show that this pandemic has had a positive impact on the cryptocurrency market. However, investors started selling cryptocurrencies as the crisis escalated. So it can be said there are limitations to this study and leads to a conclusion that the effect is critical over time and complex.

Liu (2020) analyzed the connection between the COVID-19, an infectious disease, and different financial assets. The results show that the recently identified change in the number of cases per 1,000 in the United States is an optimistic prediction of the S\&P 500 return and is negatively correlated with the change in Treasury bonds' distribution. The study shows that the change in COVID-19 newly confirmed cases per 1000 people may positively or negatively impact Treasury bonds' distribution but may not have a clear impact on the US stock market. Furthermore, the change in the newly confirmed cases per thousand people has no predictive power for Bitcoin return, whatever in the US or China.

Everyone wants an asset for their portfolio that gives a higher return with low risk. Thus searching for alternative investment instruments is a part of diversified investment portfolios. Perhaps, cryptocurrency is the one with these qualities (Kumar, Ali \& Kibria, 2021). Liu (2020) researched the bitcoin's properties in the financial market. Their research's primary purpose was to find the conditional cross effects and volatility spillover between Bitcoin and financial 
indicators and show whether the bitcoin market allows hedging the risk investment against all different financial assets. They used a statistical method DCC-GARCH to identify the potential asymmetry and persistence behaviors between the bitcoin and other financial variables. Their results concluded that a slight movement in the Bitcoin market allows hedging the risk investment against all different financial assets. They also found that the hedging strategy, including bitcoin, reduced the portfolio's risk compared to the strategy without bitcoin.

As time passes, we see considerable development in almost every sector, and so peoples transforming themselves accordingly. Similarly, now a day's the use of virtual currency is increasing rapidly. Peoples are putting their hands into it. In recent years, one of the virtual currencies, cryptocurrency, is being adopted for legal and illegal transactions - the only reason everyone is attracted towards it is its vast returns. By seeing considerable success, many other companies introduce their cryptocurrencies as well. So, to find which cryptocurrency will be suitable for future investment. Celeste, Corbet, and Gurdgiev (2020) researched some top cryptocurrencies: Bitcoin, Ethereum, and litecoin. In his study, he analyzed the trends of these cryptocurrencies. He compared them concerning their volatility and stability in recent times to predict the five-year projected value of these cryptocurrencies. He proposed the results by using linear regression, Monte Carlo analysis, and industry professionals' interviews. He concluded that bitcoin is likely to experience more growth in the five-year time horizon. Simultaneously, Ethereum can be useful for portfolio investment because of its wide range of positive and negative both and litecoin shows more minor variance than there, so it may be preferred as a new investment option.

Demir (2020) suggested that the Price volatility, long memory, and spillover return should be presented in Bitcoin, Ethereum, and Ripple's asset dynamics. The result shows that Bitcoin is useful for risk management and gives an investor an option for long-term investment. While Ethereum and Ripple have a greater variance due to correlation with speculation, investors interested in capturing higher frequency trading returns, notwithstanding Liquidity risks, should pay more attention to the evolution of Ethereum and Ripple.

Kristoufek (2020) proposed a study on the volatility of cryptocurrency, focusing on long memory properties. He used some top cryptocurrencies, namely, Bitcoin, Ethereum, and Ripple, covering $86 \%$ of the market cap and $60 \%$ of trading volume in recent years. In his study, he used several statistical software like Rescaled Range Statistics (R/S), Gaussian Semi Parametric (GSP), and the Geweke and Porter-Hudak (GPH) Model Method for testing long memory. At the same time, he uses GARCH, HYGARCH, and FIGARCH techniques for modeling. The result shows that the cryptocurrencies show the long memory to achieve a better portfolio cryptocurrency will be the potential investment tool for an investor.

In recent years, cryptocurrency made a huge success, increased prices. Cryptocurrency appears to be a trending payment and an option for an investor for portfolio investment (Ali et al., 2021; Meher, 2020). As people are considering cryptocurrency as the investment option, so to know more about it, Soylu (2020) did research in which he finds what assets are nearer to cryptocurrency and also estimated the applicability of outdated methods of evaluating financial assets to cryptocurrency. Bitcoin is produced as a commodity asset by mining through computational power, unlike fiat currency. Also, Bitcoin can be used as an instrument for the payment of goods and services. This research helps the investor to decide about the inclusion of Bitcoin in his portfolio.

Sovbetov et al. (2018) researched five cryptocurrencies that are the most common in recent days. They are Bitcoin, Ethereum, Litecoin, Dash, and Monero. In his study, he examined the factors that impact the prices of cryptocurrency. He used a statistical method ARDL technique to find the results. He found out that market beta, trading volume, and volatility are significant for all cryptocurrencies both in the long and short run. He discovers that the attractiveness of the cryptocurrency will influence its price in the long run. Notably, Bitcoin and Ethereum have a higher responsiveness to the market in the long run and short run than other cryptocurrencies. The change in trading volume affects cryptocurrencies more in the long run. Cryptocurrencies can have a more severe response to the market's volatility in the short-run than in the long run.

Saeed (2013) researched the impact of covid 19 on the top 5 cryptocurrencies, namely Bitcoin, Ethereum, litecoin, Ripple, and Binance. The study aims to find herding behavior in the cryptocurrency market and analyze the Efficiency in the cryptocurrency market before and after the coronavirus pandemic. For the results, the fractal theory was being used. The results showed that covid-19 has a positive impact on cryptocurrency market efficiency.

Cheng and Yen (2020), in their research, discovered the best opportunity for investment during the coronavirus pandemic. For this, he analyzed the effect of covid-19 on the return of some top cryptocurrencies, namely Bitcoin, Ethereum, and Tether, and global metals like gold, silver, and copper most popular and traded metal. He founded that the best investment opportunity is to invest in the cryptocurrency market according to its return. Particularly, Ethereum has the highest return, then Bitcoin and then Tether, while in the metal market, silver has the highest return, then copper and then gold.

As the time passes the world are moving towards adopting virtual currency and Bitcoin is one of the most demanded virtual currency these days. For this, Zhou (2018) researched the exchange rate movement of Bitcoin and explored that whether Bitcoin's exchange rate is related to the global financial crisis. He used the exponential Garch model to find out the results. He concludes that the bitcoin information-related events, regulation of Bitcoin-related events, and news coverage were related or impacted Bitcoin's exchange rate. Also, his finding suggests that the Bitcoin market is not 
entirely isolated from the world economy.

As Covid-19 was a nightmare for many countries and it caused significant loss to the world's economies. Romanchenko (2018) researched the effect of Covid-19 on China's stock market. He took the Google trend data of almost four months from January to April. For the results, he applied the exponential generalized autoregressive conditional heteroskedastic (EGARCH) model. In his findings, he saw that the uncertainty due to covid-19 caused China's composite index to decline significantly. Also, the stock return's volatility becomes higher for both composite index and sector indices. One thing that he noticed was that the impact of covid-19 varies according to sectors. Most sectors like transport, energy, consumer discretionary, and telecom were affected negatively, but some sectors were still affected positively, like the IT sector.

Engle (2001) researched the contagion effect during various financial crises in India, Pakistan, and Sri Lanka's stock market. He also examines the leverage effect of the studied markets. He used the exponential Garch model to find the outcomes. He found out that the analyzed markets showed the minimal impact of the 1997 South East Asian crises. Notably Indian market showed better integration with the Russian and Brazilian crises, while Pakistan and Sri Lanka showed better integration or higher volatility with the 9/11 crises. The findings suggest that the South Asian markets are now getting more integrated with the global financial system and are more likely to see the upcoming period's contagion effect. All the South Asian markets experienced higher volatility during the 2008 global crisis. The results showed that the crises in other markets would affect South Asian markets more than the positive shocks in other markets for the leverage effect.

Mnif, Jarboui, and Mouakhar (2020) tried to check the presence of leverage effect of covid-19 on price volatility of crude oil and natural gas, measured by taking everyday prices of both the commodities into account. The results reveal that crude oil's price volatility has a leverage effect of covid-19 present and no leverage effect found in natural gas. The research findings are significant as they will help investors develop appropriate investment stratagems and help policymakers formulate policies to minimize the impact of covid-19.3.

\section{DATA AND METHODOLOGY}

This study used the daily prices of Bitcoin, Ethereum, XRP(Ripple), Litecoin and considered COVID-19 as the "bad news" in the economy. COVID-19's daily cases from 08th January 2020 to 09th August 2020 from statista.com were taken into account. The everyday prices of all the four cryptocurrencies for 10th August 2017 till 09th August 2020 have been taken from the website coinbase.com. Log daily returns and Augmented dickey-fuller test (ADF) has been used to check the data's stationarity. Exponential generalized autoregressive conditional heteroscedastic (EGARCH) is used to formulate the model for price volatility. The EGARCH model has been used as it is the best method to predict the price volatility, and we can also find the leverage effect using EGARCH, which would not be possible if we used the GARCH model. Stata 16 has been used to execute all the tests. The following formula is for the EGARCH model.

$\log \left(h_{t}\right)=\varphi+\sum_{i=1}^{q} n_{i}\left|\frac{u_{t}-i}{\sqrt{h_{t}-i}}\right|+\sum_{i=1}^{q} \lambda_{i} \frac{u_{t}-i}{\sqrt{h_{t}-i}}+\sum_{k=1}^{p} \theta_{k} \log \left(h_{t-k}\right)$

Where;

$\log (h)=\log$ of variance or $\log$ returns

$\varphi=$ Constant

$n_{i}=\mathrm{ARCH}$ Effects

$\lambda_{i}=$ Asymmetric effects

$\theta=\mathrm{GARCH}$ effects

\section{RESULTS AND DISCUSSION}

Before we formulate the EGARCH model, we need to check that all the cryptocurrencies' data are stationary. For this purpose, the unit root test, i.e., the Augmented Dickey-Fuller test, has been applied.

The price volatility or log-returns of bitcoin, Litecoin, Ripple, and Ethereum can be seen from figure 1a-1d. It indicates volatility clustering for all cryptocurrencies, which means significant variations and small variations track large variations are tracked by small variations, implying that the volatility model can be framed. It is visible from figure 1 a that there have been large fluctuations for bitcoin before the year 2020, but the largest fluctuation took place in the first quarter of 2020. In fig $1 \mathrm{~b}$ and 1 c, larger price fluctuations can be seen at the beginning of 2017 and 2020 for both Litecoin and Ripple, which also marks the entrance of covid-19. In contrast, in fig 1d, there are large fluctuations before the year 2020, but the largest fluctuation took place in the first quarter of 2020. 


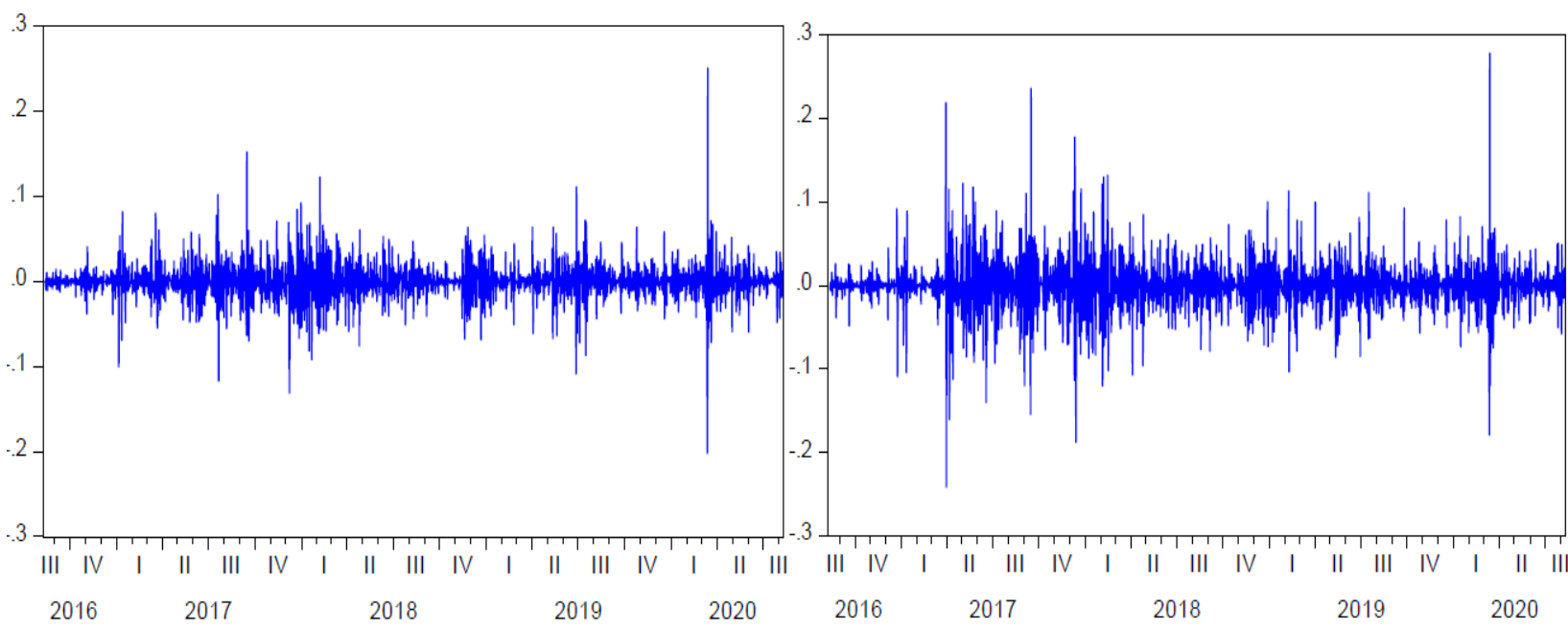

1-a(Log returns of Bitcoin)

1-b (Log returns of Litecoin)
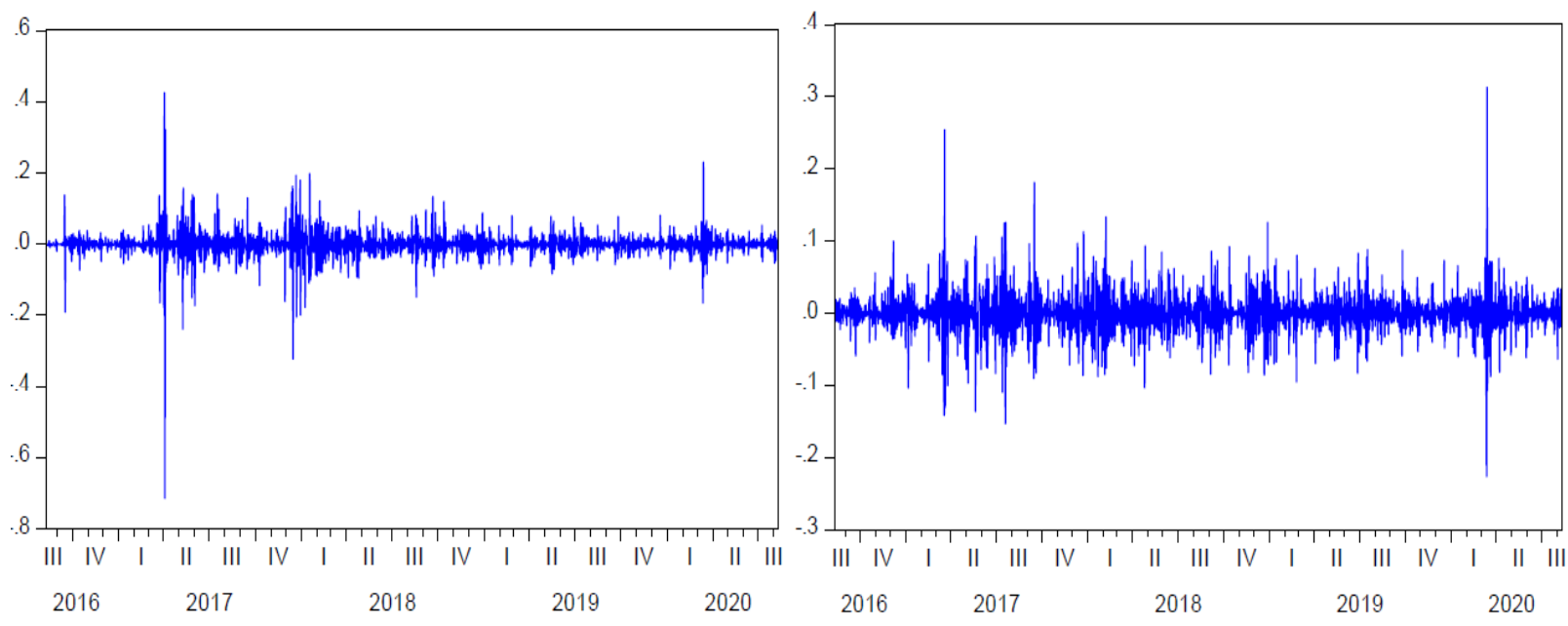

1-c (Log returns of Ripple)

1-d (Log returns of Ethereum)

Figure 1 (a-d): Price volatility of Cryptocurrencies

Source: Stata 16 Output

The data of Bitcoin, Litecoin, Ripple, and Ethereum are all leptokurtic (fig 2a-2d). Also, the values of Skewness, kurtosis, and Jarque- Bera statistics verify the conclusion.

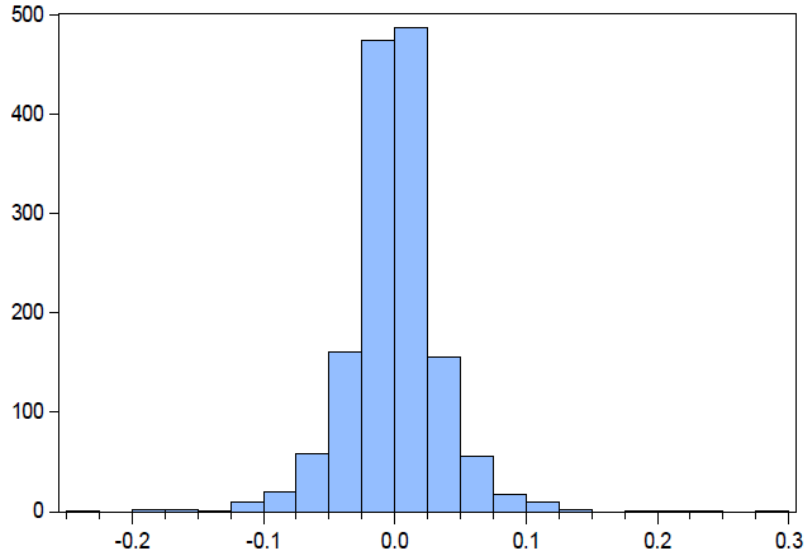

\begin{tabular}{|ll|}
\hline \multicolumn{2}{|l|}{ Series: LITECOINL } \\
Sample $8 / 10 / 20168 / 09 / 2020$ \\
Observations & 1459 \\
Mean & $-6.71 \mathrm{e}-06$ \\
Median & 0.000000 \\
Maximum & 0.277959 \\
Minimum & -0.241371 \\
Std. Dev. & 0.036439 \\
Skewness & 0.246809 \\
Kurtosis & 10.79942 \\
& \\
Jarque-Bera & 3712.831 \\
Probability & 0.000000 \\
\hline
\end{tabular}

(a) 


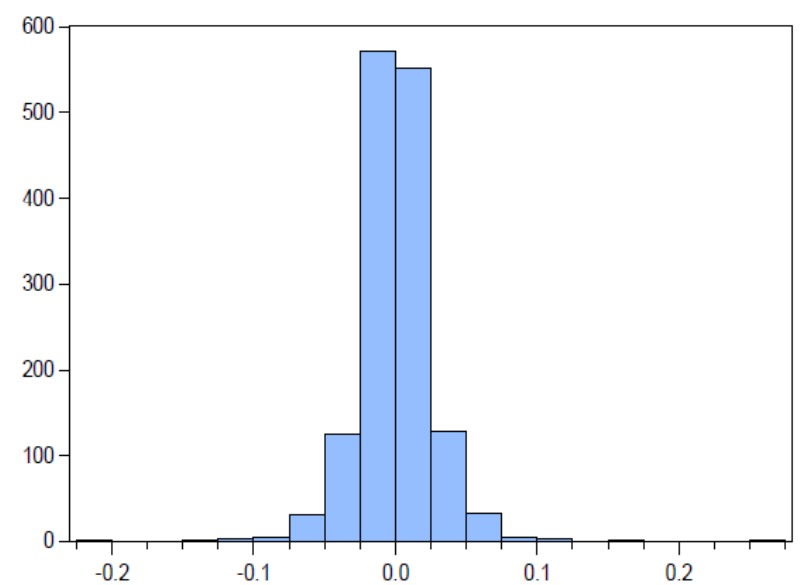

\begin{tabular}{|ll|}
\hline Series: BITCOINL \\
Sample 8/10/2016 8/09/2020 \\
Observations & 1459 \\
& \\
Mean & $-4.88 \mathrm{e}-07$ \\
Median & -0.000111 \\
Maximum & 0.250769 \\
Minimum & -0.201923 \\
Std. Dev. & 0.025956 \\
Skewness & 0.373348 \\
Kurtosis & 14.00346 \\
& \\
Jarque-Bera & 7394.308 \\
Probability & 0.000000 \\
\hline
\end{tabular}

(b)

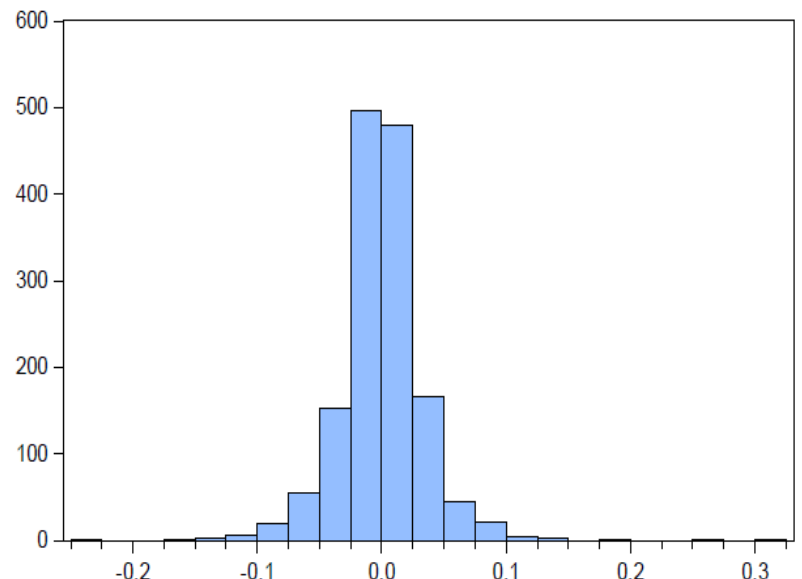
Series: ETHEREUML
Sample 8/10/2016 8/09/2020
Observations 1459
Mean $\quad 9.07 \mathrm{e}-06$
Median $\quad-9.44 \mathrm{e}-05$
Maximum $\quad 0.313103$
Minimum $\quad-0.226218$
Std. Dev. $\quad 0.034629$
Skewness $\quad 0.571765$
Kurtosis $\quad 12.28751$
Jarque-Bera $\quad 5323.255$
Probability $\quad 0.000000$

(c)

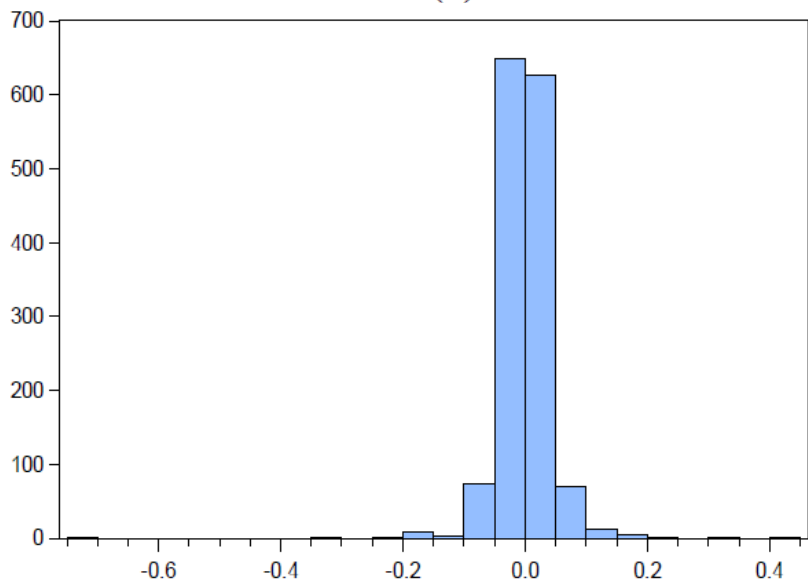

\begin{tabular}{|lc|}
\hline \multicolumn{2}{|l|}{ Series: XRPL } \\
Sample 8/10/2016 8/09/2020 \\
Observations & 1459 \\
& \\
Mean & $-5.25 \mathrm{e}-06$ \\
Median & -0.000322 \\
Maximum & 0.425807 \\
Minimum & -0.713819 \\
Std. Dev. & 0.044802 \\
Skewness & -2.225937 \\
Kurtosis & 58.66850 \\
& \\
Jarque-Bera & 189597.1 \\
Probability & 0.000000 \\
\hline
\end{tabular}

(d)

Figure 2 (a-d): Peak of Cryptocurrencies

\section{Source: Stata 16 Output}

The observed R squared statistics are 54.84047, 50.13226, 54.69346, and 49.44266, respectively, and are significant because of $\mathrm{P}<0.05$. Further, $\mathrm{F}$ statistics are 73.16244, 64.94784, 72.89856, and 63.78436, respectively, and are significant because for all of them, $\mathrm{P}<0.05$. This shows that the ARCH effect is present in all of them. Hence EGARCH model can be applied. After checking the ARCH effect in all four cryptocurrencies' data, we move towards applying the EGARCH $(1,1)$ model with the Gaussian distribution construct. We need to make sure there is no heteroscedasticity, and there is no Autocorrelation.

Table 1 shows the result of the EGARCH $(1,1)$ model of Bitcoin. EGARCH results are divided into two portions: the upper portion forms the main equation, and the lower portion forms the variance equation. The constant (C) coefficient in the main equation is considered weak as its probability value is not $<0.05$, which means it is non-significant. The coefficient of Bitcoin is considered significant as its probability is $<0.05$. Since the probability values of all the 
coefficients in the variance equation are $<0.05$, they can be taken as significant. To see the leverage effect, we focus on the value of $C(5)$, which is the asymmetric term's coefficient $(\lambda)$. The value of $C(5)$ is positive at 0.324936 and is significant as $\mathrm{P}<0.05$. It means that the leverage effect on the price volatility of bitcoin does not exist. The variance equation of Bitcoin is stated below;

$$
\log \left(h_{t}\right)=-0.740007+\sum_{i=1}^{q} 0.544552\left|\frac{u_{t}-i}{\sqrt{h_{t}-i}}\right|+\sum_{i=1}^{q} 0.324936 \frac{u_{t}-i}{\sqrt{h_{t}-i}}+\sum_{k=1}^{p} 0.952950 \log \left(h_{t-k}\right)
$$

Table 2 shows EGARCH $(1,1)$ model with Gaussian distribution construct. In the main equation, the constant (c) is insignificant and is considered weak as $\mathrm{P}>0.05$, whereas litecoinL $(-1)$ is significant as $\mathrm{P}<0.05$. In the variance equation, $\mathrm{C}(4)$ and $\mathrm{C}(6)$ are insignificant as the probability is greater than

0.05 , whereas the other two coefficients are significant. Asymmetric co-efficient $(\lambda)$ is negative and significant, indicating that the price volatility of the Lite coin has a leverage effect of COVID-19 present.

$$
\log \left(h_{t}\right)=-9.413622+\sum_{i=1}^{q} 0.136317\left|\frac{u_{t}-i}{\sqrt{h_{t}-i}}\right|-\sum_{i=1}^{q} 0.381035 \frac{u_{t}-i}{\sqrt{h_{t}-i}}-\sum_{k=1}^{p} 0.258142 \log \left(h_{t-k}\right)
$$

\begin{tabular}{|c|c|c|c|c|}
\hline Variable & Co-efficient & Std. Error & z-Statistic & P-Value \\
\hline $\mathrm{C}$ & 0.001374 & 0.001165 & 1.180008 & 0.2380 \\
\hline BITCOIN(-1) & -0.752837 & 0.061909 & -12.16037 & 0.0000 \\
\hline \multicolumn{5}{|l|}{ Variance Equation } \\
\hline$\overline{C(3)}$ & -0.740007 & 0.198164 & -3.734322 & 0.0002 \\
\hline $\mathrm{C}(4)$ & 0.544552 & 0.084139 & 6.472071 & 0.0000 \\
\hline $\mathrm{C}(5)$ & 0.324936 & 0.064688 & 5.023149 & 0.0000 \\
\hline$C(6)$ & 0.952950 & 0.023351 & 40.81022 & 0.0000 \\
\hline R-Squared & 0.375375 & Mean dependent var & $7.38 \mathrm{E}-06$ & \\
\hline Adj R-Squared & 0.372429 & S.D. dependent var & 0.030798 & \\
\hline S.E. of regression & 0.024398 & Akake info criterion & -5.000770 & \\
\hline Sum squared resid & 0.126193 & Schwarz criterion & -4.906396 & \\
\hline Log likelihood & 541.0824 & Hannan-Quality criter & -4.962634 & \\
\hline Durbin Watson Stat & 2.149669 & & & \\
\hline
\end{tabular}

Table 1: Results of EGARCH $(1,1)$

Source: Stata 16 Output

\begin{tabular}{|c|c|c|c|c|}
\hline Variable & Co-efficient & Std. Error & tic & P-Value \\
\hline $\mathrm{C}$ & -0.001122 & 0.001912 & -0.586685 & 0.5574 \\
\hline LITECOINL(-1) & -0.492705 & 0.030952 & -15.91839 & 0.0000 \\
\hline \multicolumn{5}{|l|}{ Variance Equation } \\
\hline $\mathrm{C}(3)$ & -9.413622 & 1.599550 & -5.885169 & 0.0000 \\
\hline $\mathrm{C}(4)$ & 0.136317 & 0.111871 & 1.218518 & 0.2230 \\
\hline$C(5)$ & -0.381035 & 0.079456 & -4.795552 & 0.0000 \\
\hline $\mathrm{C}(6)$ & -0.258142 & 0.210739 & -1.224937 & 0.2206 \\
\hline R-Squared & 0.389910 & Mean dependent var & $-9.15 \mathrm{E}-07$ & \\
\hline Adj R-Squared & 0.387033 & S.D. dependent var & 0.035983 & \\
\hline S.E. of regression & 0.028172 & Akake info criterion & -4.510416 & \\
\hline Sum squared resid & 0.028172 & Schwarz criterion & -4.416043 & \\
\hline Log likelihood & 488.6145 & Hannan-Quality criter & -4.472280 & \\
\hline Durbin Watson Stat & 2.606639 & & & \\
\hline
\end{tabular}

Table 2: Results of EGARCH $(1,1)$

\section{Source: Stata 16 Output}

Table 3 shows EGARCH $(1,1)$ model with Gaussian distribution construct. The table includes two equations, i.e., the main equation and the variance equation. In the main equation, the constant (c) is insignificant, which means; it is considered weak as $\mathrm{P}>0.05$, whereas $\mathrm{XRPl}(-1)$ is significant as $\mathrm{P}<0.05$. C (6) is insignificant as the probability is greater than 0.05 , whereas the other coefficients are significant. Asymmetric co-efficient $(\lambda)$ is negative and significant, indicating the leverage effect of COVID-19 on Ripple's price volatility. It also indicates that the spreading of COVID-19 has a larger effect on the volatility of Ripple.

The variance equation is as follows; 


$$
\log \left(h_{t}\right)=-8.140699+\sum_{i=1}^{q} 0.513420\left|\frac{u_{t}-i}{\sqrt{h_{t}-i}}\right|-\sum_{i=1}^{q} 0.477409 \frac{u_{t}-i}{\sqrt{h_{t}-i}}-\sum_{\dot{k}=1}^{p} 0.006140 \log \left(h_{t-k}\right)
$$

Table 4 shows the result of the EGARCH(1,1) model of Ethereum. The constant in the main equation's coefficient is considered weak as its probability value is not $<0.05$, which means it is not non-significant. The coefficient of EthereumL(-1) is considered significant as its probability is $<0.05$. In the variance equation, all the coefficients' probability values are <0.05; they can be taken as significant. But $\mathrm{C}(5)$ is non-significant as its probability value is not $<0.05$. To see the leverage effect, we focus on the value of the asymmetric term's coefficient $(\lambda)$. $C(5)$ value is negative, that is -0.003882 and weak as its probability value is not $<0.05$. This means that the leverage effect on the price volatility of Ethereum is present, but only a weak argument can be made.

The variance equation is stated below;

$$
\log \left(h_{t}\right)=-0.550076+\sum_{i=1}^{q} 0.375884\left|\frac{u_{t}-i}{\sqrt{h_{t}-i}}\right|-\sum_{i=1}^{q} 0.003882 \frac{u_{t}-i}{\sqrt{h_{t}-i}}+\sum_{k=1}^{p} 0.962896 \log \left(h_{t-k}\right)
$$

\begin{tabular}{|c|c|c|c|c|}
\hline Variable & Co-efficient & Std. Error & z-Statistic & P-Value \\
\hline $\mathrm{C}$ & -0.000375 & 0.001478 & -0.253501 & 0.7999 \\
\hline XRPL(-1) & -0.485118 & 0.049313 & -9.837595 & 0.0000 \\
\hline \multicolumn{5}{|l|}{ Variance Equation } \\
\hline $\mathrm{C}(3)$ & -8.140699 & 1.829220 & -4.450366 & 0.0000 \\
\hline $\mathrm{C}(4)$ & 0.513420 & 0.116242 & 4.416823 & 0.0000 \\
\hline $\mathrm{C}(5)$ & -0.477409 & 0.058950 & -8.098505 & 0.0000 \\
\hline$C(6)$ & -0.006140 & 0.231130 & -0.026563 & 0.9788 \\
\hline R-Squared & 0.366374 & Mean dependent var & $-9.54 \mathrm{e}-06$ & \\
\hline Adj R-Squared & 0.363385 & S.D. dependent var & 0.030339 & \\
\hline S.E. of regression & 0.024207 & Akake info criterion & -4.829620 & \\
\hline Sum squared resid & 0.124230 & Schwarz criterion & -4.735247 & \\
\hline Log likelihood & 2.538504 & Hannan-Quality criter & -4.791485 & \\
\hline Durbin Watson Stat & 2.538504 & & & \\
\hline
\end{tabular}

Table 3: Results of EGARCH $(1,1)$

Source: Stata 16 Output

\begin{tabular}{|c|c|c|c|c|}
\hline Variable & Co-efficient & Std. Error & z-Statistic & P-Value \\
\hline $\mathrm{C}$ & -0.001216 & 0.001370 & 0.887673 & 0.2747 \\
\hline $\begin{array}{l}\text { ETHEREUML }(-1) \\
\text { Variance Equation }\end{array}$ & -0.619109 & 0.067203 & -9.212536 & 0.0000 \\
\hline $\mathrm{C}(3)$ & -0.550076 & 1.829220 & -2.959396 & 0.0031 \\
\hline $\mathrm{C}(4)$ & 0.375884 & 0.116242 & 6.269675 & 0.0000 \\
\hline$C(5)$ & -0.003882 & 0.058950 & -0.031435 & 0.9749 \\
\hline$C(6)$ & 0.962896 & 0.231130 & 41.55201 & 0.0000 \\
\hline R-Squared & 0.385817 & Mean dependent var & $1.77 \#-05$ & \\
\hline Adj R-Squared & 0.382920 & S.D. dependent var & 0.038901 & \\
\hline S.E. of regression & 0.030558 & Akaike info criterion & -4.539546 & \\
\hline Sum squared resid & 0.197969 & Schwarz criterion & -4.445173 & \\
\hline Log-likelihood & 491.7314 & Hannan-Quality criterion & -4.501411 & \\
\hline Durbin Watson Stat & 2.333250 & & & \\
\hline
\end{tabular}

Table 4: Results of EGARCH $(1,1)$

Source: Stata 16 Output

\section{CONCLUSION}

Our study results reveal that the leverage effect of COVID-19 on the volatility of the price of Litecoin, Ethereum, and Xrp (Ripple) exists. However, no leverage effect of COVID-19 was found on Bitcoin. Asymmetric terms $(\lambda)$ of Bitcoin, Xrp (Ripple), and Litecoin are significant. The coefficient of Ethereum is insignificant.

\section{LIMITATION AND STUDY FORWARD}

This study has deployed contagion effects of COVID-19 pandemic on cryptocurrencies widely used across the globe by investors like BITCOIN, LITECOIN, XRP(RIPPLE), and ETHEREUM, however other cryptocurrencies like Cardano 
(ADA), Polkadot (DOT), Stellar (XLM), Chainlink, Binance Coin (BNB), Tether (USDT), and Monero (XMR) can also be used for future studies.

\section{RECOMMENDATIONS}

Based on the current study outcomes, investors worldwide should use Bitcoin as COVID-19 as it has adversely affected most of the world's economic sectors and currencies and particular cryptocurrencies. However, Bitcoin was the currency that does not fluctuate its value in the COVID-19 outbreak, and no leverage effect was found.

\section{AUTHORS' CONTRIBUTIONS}

Mahboob Ullah: Data Analysis and its interpretation, Abstract and Conclusion writing, review of the article after completion, and correspondence with the journal.

Maria Shaikh: Data Collection, working on Literature, writing references and after completion of research review the article.

Imran Abbas Jadoon: Data Collection, working on Literature and after completion of research, its review.

Muhammad Azizullah Khan: Data Collection, working on Literature and after completion of research, its review.

Shahida Habib Alizai: Data Collection, working on Literature and after completion of research, its review.

\section{REFERENCES}

1. Ali, S. R. (2020). The pattern, sources, and growth of remittances to Pakistan: The kinked exponential approach. Journal of Research in Emerging Markets, 2(1):1-6. https://doi.org/10.30585/jrems.v2i1.383

2. Abdelrhim, M., Elsayed, A., Mohamed, M., \& Farouh, M. (2020). Investment opportunities in the time of (covid-19) spread: the case of cryptocurrencies and metals markets. https://doi.org/10.2139/ssrn.3640333

3. Baker McKenzie. (2020), International: The Impact of COVID-19 on the Oil and Gas Industry. https://www.bakermckenzie.com; https://www.bakermckenzie.com/en/insight/publications/2020/04/the-impactof-covid19-on- the-oil-and-gas-industry

4. Bhosale, J., \& Mavale, S. (2018). The volatility of select cryptocurrencies: a comparison of bitcoin, ethereum, and litecoin. Annual Research Journal of SCMS, Pune, 6, 97-105.

5. Celeste, V., Corbet, S., \& Gurdgiev, C. (2020). Fractal dynamics and wavelet analysis: deep volatility and return properties of bitcoin, ethereum, and Ripple. The Quarterly Review of Economics and Finance, 76, 310324. https://doi.org/10.1016/j.qref.2019.09.011

6. Cheng, H. P., \& Yen, K. C. (2020). Does COVID-19 affect the financial market?. Available at SSRN 3578263. https://doi.org/10.2139/ssrn.3578263

7. Demir, E., Bilgin, M. H., Karabulut, G., \& Doker, A. C. (2020). The relationship between cryptocurrencies and COVID-19 pandemic. Available at SSRN 3585147. https://doi.org/10.2139/ssrn.3585147

8. Engle, R. (2001), GARCH 101: The Use of ARCH/GARCH models in applied econometrics. Journal of Economic Perspectives, 15(4), 157-168. https://doi.org/10.1257/jep.15.4.157

9. Guesmi, K., Saadi, S., Abid, I., \& Ftiti, Z. (2019). Portfolio diversification with virtual currency: Evidence from bitcoin. International Review of Financial Analysis, 63, 431-437. https://doi.org/10.1016/j.irfa.2018.03.004

10. Harvey, A., Sucarrat, G. (2014), EGARCH models with fat tails, Skewness and leverage. Computational Statistics and Data Analysis, 76(1), 320-338. https://doi.org/10.1016/j.csda.2013.09.022

11. Iqbal, T.H., Mallikarjunappa, T. (2010), A study of Efficiency of the Indian stock market. Indian Journal of Finance, 4(5), 32-38.

12. Iqbal, T.H., Mallikarjunappa, T. (2011), Efficiency of the stock market: a study of stock price responses to earnings announcements. Germany: LAP Lambert Academic Publishing Company.

13. Jabotinsky, H. Y., \& Sarel, R. (2020). How crisis affects crypto: coronavirus as a test case. Available at SSRN 3557929. https://doi.org/10.2139/ssrn.3557929

14. Khan, A. M., Ullah, M., Usman, A., Malik, A. H., Khan, K. M. (2020). Impact of covid-19 on the global economy. International Journal of Management, 11(8), 2020, pp. 956-969

15. Kristofer, L. (2020). Grandpa, grandpa, tells me about Bitcoin being a haven: evidence from the COVID-19 pandemics. arXiv preprint arXiv:2004.00047. https://doi.org/10.3389/fphy.2020.00296

16. Kumar, B., Ali, S. R., \& Kibria, M. G. (2021). International remittances, household welfare, and women Empowerment: evidence from Bangladesh. In Dixit, S., \& Moid, S. (Ed.), 174-190). https://doi.org/10.4018/9781-7998-3737-4.ch012

17. Liu, K. (2020). The Effects of COVID-19 on Chinese stock markets: an arch approach. https://doi.org/10.1108/JCEFTS-08-2020-0055

18. Meher, B. K., Hawaldar, I. T., Mohapatra, L., \& Sarea, A. (2020). The Impact of COVID-19 on price volatility of crude oil and natural gas listed on multi commodity exchange of India. International Journal of Energy Economics and Policy, 10(5), 422-431. https://doi.org/10.32479/ijeep.10047

19. Mnif, E., Jarboui, A., \& Mouakhar, K. (2020). How the cryptocurrency market has performed during COVID 19? A multifractal analysis. Finance Research Letters, 101647. https://doi.org/10.1016/j.frl.2020.101647 
20. Mukherjee, I., Goswami, B. (2017), The volatility of returns from commodity futures: Evidence from India. Financial Innovation, 3(15), 1-23. https://doi.org/10.1186/s40854-017-0066-9

21. Romanchenko, O., Shemetkova, O., Piatanova, V., \& Kornienko, D. (2018). The approach of estimation of the fair value of assets on a cryptocurrency market. 2018 International Conference on Digital Science (pp. 245 253). Springer, Cham. https://doi.org/10.1007/978-3-030-02351-5 29

22. Saeed, S. K., Riaz, K., \& Ayub, U. (2013). Financial contagion in South Asia: an EGARCH approach. American Journal of Scientific Research, 85-105. https://doi.org/10.2139/ssrn.2241389

23. Soylu, P. K., Okur, M., Çatıkkaş, Ö., \& Altintig, Z. A. (2020). Long memory in the volatility of selected cryptocurrencies: bitcoin, ethereum, and Ripple. Journal of Risk and Financial Management, 13(6), 107. https://doi.org/10.3390/jrfm13060107

24. Sovbetov, Y. (2018). Factors influencing cryptocurrency prices: Evidence from bitcoin, ethereum, dash, bitcoin, and monero. Journal of Economics and Financial Analysis, 2(2), 1-27.

25. Syed Rashid Ali, Muhammad Waqar Khan, Zeeshan Atiq and Muhammad Wajahat Ali, (2021). The impact of geographical distance on remittances: a case study of the Pakistani diaspora. International Journal of Management, 12(1), pp 65-72.

26. Ullah, M., Shaikh, M., Channar, P., \& Shaikh, S., (2021). Financial forecasting: an individual perspective. International Journal of Management, 12(3), 60-69.

27. Yarovaya, L., Matkovskyy, R., \& Jalan, A. (2020). The effects of a black swan event (covid-19) on herding behavior in cryptocurrency markets: evidence from cryptocurrency USD, EUR, JPY, and KRW Markets. EUR, JPY, and KRW Markets. Finance Research Letters, 101897. https://doi.org/10.2139/ssrn.3586511

28. Zhou, S. (2018). Exploring the driving forces of the bitcoin exchange rate dynamics: an EGARCH. Journal of Finance, 49(3), 923-950. 